an excellent auxiliary to our treatment; but, it must also be borne in mind, that in every case treated by camphor, except one, (Dr. Pidduck's, in which the dose of strychnia was comparatively small, ) other remedies-and amongst them emeticswere given. It can, therefore, scarcely be said to answer all our requirements. Charcoal is said to act upon poisons by their adhering to its surface, and so being removed from contact with the stomach; and tannin by producing an insoluble com. pound with the strychnia. Neither of these, therefore, can exert any beneficial effect beyond what takes place with the unabsorbed poison. The experiments of Dr. Hammond, of Fort Riley, show that no reliance can be placed on fat as an antidote.

I now proceed to examine the claims of emetics to effect our object-or rather I would say vomiting; and to prove that this is the agent I will draw attention to its effects in some diseases manifesting phenomena not very dissimilar from those caused by the poison under consideration. I allude to those disorders having a paroxysmal or spasmodic characternamely, whooping-cough, hysteria, and infantile convulsions. In all these, in common with strychnia poisoning, we have, first, the periodical return of the paroxysm or spasm; secondly, the intermittent and irregular performance of the function of respiration; and, thirdly, a dark and highly carbonized condition of the blood. My attention was many years ago directed to a fact which is no doubt familiar to the profession, that the paroxysm of whooping-cough is almost invariably cut short by a good fit of vomiting, and that the countenance, which before was dusky from the circulation of highly carbonized blood, soon becomes florid and animated; the respiration, which before the fit was laboured and irregular, now becomes free and easy, and the child returns to its play or its meals. In the convulsions of children we have the same irregular, intermittent, and imperfect performance of the function of respiration, and the same irregular distribution, generally diminution of animal heat.

Reflecting on the results of vomiting on the paroxysm of whooping-congh, I was induced to try it in convulsions, and, where I could obtain it, have never found it fail in removing the convulsion.

In the allied disease of hysteria, where a very similar condition of the respiratory organs and functions exists, the breathing here being irregular, imperfect, and often at distant intervals, and where the external manifestations very much resemble those we have been considering, I have for many years looked upon vomiting as the remedy above all others to be relied on to remove the paroxysm or fit.

In the cases above mentioned it would be unfair to regard the mere emptying of the stomach as the ratio medendi. I have long since come to the conclusion that the return to healthy respiration has more to do with the relief of these diseases than is generally admitted. I believe the experiments of Dr. Harley have led him to the conclusion that strychnia prodnces death, not by its action on the nerve substance, but on the blood, by destroying its capability to absorb oxygen. This theory appears to derive considerable strength from the fact of the blue or dusky condition of the skin in the subjects of poisoning by strychnia, indicating a highly carbonized state of the blood. It has been suggested by Dr. Brown-Séquard, that in many cases of poisoning the loss of animal heat tends to a fatal result. Now, what is the meaning of this fact but that it is in consequence of the respiration being imperfectly and insufficiently performed, and, the circulation through the lungs having been thereby - impeded, that the blood is not passing with its accustomed energy through the capillaries, and this tendency to death takes place? A similar condition to this must exist in the cold stage of fevers; and here we give emetics--and what for, if not to bring about, by the action of vomiting, a more complete and full respiratory action, and a more perfect series of that action, by which the blood is more quickly driven through the lungs, causing an increased absorption of oxygen, and a consequent greater development of animal heat, with its more general diffusion over the body? These results of vomit. ing, which are self evident, cannot be the effect of the mere evacuation of the contents of the stomach; they must therefore be accomplished by the physiological action of vomiting. If this be true, then, we have, in vomiting, a real and true antidote to poisoning by strychnia; and it is by the maintenance of the condition of system thereby induced that we must reasonably hope to combat the two morbid effects of the poison which are said to tend to death-I mean the diminished capacity of the blood for oxygen, and the consequent falling of the animal heat.
But although I believe we have sufficient evidence to prove that this alone, when freely accomplished, is of itself sufficient to prevent death, yet I would not limit the treatment entirely to its production; for after the evidence we have had of the power of chloroform to subdue the spasms, I think we shall consult the comfort and ease of our patients by its careful ex. hibition, but I do not think it should be carried to the pitch of producing complete insensibility, nor, indeed, beyond the degree which causes the breathing to become regular. When the sickness has somewhat subsided, we may give camphor, suspended in almond emulsion, or any other fitting vehicle. With a view of assisting to maintain the animal warmth, I would place the patient near a good fire, or keep him well covered with blankets. It is of the utmost importance that the most perfect quiet should be observed by the patient and those about him, since it is obvious that any touch of the surface, or movement of any attendant in contact with the patient, may bring on a paroxysm of tetanic spasm, which might prove fatal. During the very sovere fit, I believe we derived most timely aid from cold affusion, which appeared to bring on inspiration, and restore the then suspended animation. These remedies, though useful auxiliaries, are quite subordinate to the more important act of vomiting.

When once vomiting has been brought on, we should assist it by copious draughts of warm water, which will prolong the sickness, and also render it less painful. As regards the kind of emetic to be used, of course we give the preference to those of a non-depressing character; and were I to see another case, I should be disposed to use mustard, as being quicker in its operation than all others. Sulphate of zinc and ipecacuanha, however, afford a very appropriate form.

Camden-road Villas, March, 1861.

\section{ON THE CONTAGION OF YELLOW FEVER.}

$$
\text { By W. BUDD, M.D., Clifton. }
$$

AFTER the vague platitudes to which we have so long been accustomed whenever the subject of epidemics is in question, it is a pleasure to read the remarks made by Dr. $M^{\prime} W$ William in his manly and sensible speech on the interesting account, lately given to the Epidemiological Society by Dr. Bryson, of the introduction of yellow fever into Port Royal, Jamaica. The two precautions on which he so ably insisted, in their application to future outbreaks, do not, however, comprise all that may be done in the way of prevention. To run infected ships out of the tropics, and, whether on board ship or on shore, to maintain as strict a separation as possible between the sick and the healthy, are not the only precepts of first-rate importance suggested by the contagious nature of this fearful malady and the known thermometrical conditions required for its propagation. To destroy the contagious properties of the black vomit, and of the other excretions, immediately on their issue from the body, is, to say the least, as essential in many cases, if we wish to limit the sphere of the infection. Whenever a contagious disorder is attended by discharges that are characteristic of it, these discharges are always (as I have elsewhere endeavoured to show) the chief vehicle of the morbid poison. They originate, in fact, in, and are the outward mark of, the very act of elimination. It is from this intimate connexion with the specific poison, in each particular case, that such discharges derive their special character. I need scarcely add that yellow fever offers no exception to this law. It would occupy too much space to give in detail the decisive evidence by which it may be shown that the black vomit and the secretions of the same kind which issue from the bowel have a very large if not the principal part in the propagation of this pestilence. It may be sufficient to state, here, that this conclusion may be deduced with the utmost certainty from already existing data. By their nature as well as their amount, these discharges are eminently fitted to spread and carry out, over a wide sphere, the work of dissemination. In malignant attacks the quantity of fluid thrown off by the stomach, in the shape of the characteristic black vomit, is often absolutely enormous, In many subjects a similar fluid is discharged in floods by the bowels also. At sea, it saturates not only the bedding and the other furniture, but the timbers of the ship also, which it in- 
fects with a long-abiding taint. On shore, it poisons the latrine or privy, or, worse still, some drain, gutter, or open ditch that may happen to be at hand. In either case, the noxious matter, once cast forth, fills the air with contagious exhalations.

It is essential to a true view of the events to understand that the atmosphere thus generated is, in all probability, immeasurably more infectious than that which immediately surrounds the fever patient. In many instances, not only is the air poisoned, but the virus, percolating through the soil, finds its way into the drinking water also.

The circumstances here pointed out explain perfectly all that is most characteristic in the dissemination of this fatal malady. They explain-

1st. The well-ascertained relation of this dissemination to defective drainage.

2nd. The frequent occurrence of the disease in persons who have held no communication with the sick, and under circum. stances that not only do not bear the common resemblance of contagion, but seem at first sight to preclude its operation.

3rd. The entire failure experienced in so many cases of the mere separation of the sick from the healthy, however strictly carried out, in preventing the spread of the disorder.

4th. The peculiar fatality of yellow fever in barracks and other establishments, a part of whose economy $i_{i}^{t}$ is to have common privies for the use of large numbers of persons, and which are at once the receptacles of discharges from the sick and the daily resort of the healthy.

5th. The frequent decimation of the inmates of one wing of a barrack or other public building, while in an adjoining or nearly contiguous wing, identical with the other in every sanitary condition except in having a latrine of its own, all the inmates have remained perfectly healthy.

And, lastly, they explain perfectly the still more striking fact; (inexplicable on any other grounds, ) of which there have, I believe, been many examples, in which, in large public establishments containing persons of both sexes, one sex has suffered from the fever in an extreme degree, while the other has entirely escaped.

To separate the healthy, however strictly, from the fever patients, but to allow them still to come into intimate contact with the most specific of all the fever exuvia, is a proceeding that may be described as worse than futile. It is mnch as if, in the case of small-pox, we should take the utmost care to separate the uninfected from the small pox patient, aud still to allow them to come into contact with things and places tainted in the highest degree with the small-pox virus.

In the spring of 1859 , when yellow fever committed such havoc amongst the troops at Trinidad, I drew up, for the use of a friend who was about to join his regiment there, a little code of precautionary measures, from which the following are ex. tracted:-

a. All discharges from the sick (including especially the characteristic black vomit) to he received, on their issue from the body, if possible, into vessels containing a saturated solution of chloride of zinc. Such portions of these discharges as may be unavoidably spilt, or scattered about, to be covered at once with peat charcoal and chloride of lime.

b. The latrines, or other places which serve as the final receptacles of these discharges, to be reserved exclusively for that use.

c. All latrines or privies to be thickly strewed night and morning with a mixture of equal parts of peat charcoal and chloride of lime.

d. All tainted linen to be burnt immediately on its removal frôn the sick.

$e$. The hands of all attendants on the sick to be frequently and carefully washed, especially after being soiled by black vomit or other discharges.

$f$. The utmost care to be taken in providing pure drinking water, and where any doubt may exist as to its quality, the water to be boiled and filtered through charcoal before use.

g. The interior of infected barracks and other places to be well fumigated with chlorine, and afterwards white-washed and painted. Existing privies, and all drains connected with them, if. infected with yellow-fever discharges to be built over or otherwise abolished, after a preliminary disinfection.

$h$. The attendants on the sick, and those engaged in disinfecting operations, to be chosen (in accordance with Sir W. Pym's suggestion) from persons who have had the fever before, when such persons are to be had.

i. Convalescents to be kept for some time in strict separation from the uninfected.

Do whit we may, it will probably be impossible to prevent the spread of yellow fever in all cases. But by combining the measures here described with the precautions suggested by Sir W. Pym and other writers, and so ably enforced by Dr. M'William, there can be little doubt that its ravages may be very greatly limited.

March, 1861.

\section{a iftirrux}

OF THE PRACTICE OF

\section{MEDICINE AND SURTERT IN THE}

\section{HOSPITALS OF LONDON.}

Nulla est alia pro certo noscendi via, nisi quam plurimas et morborum es dissectionum historias, tam aliorim proprias, collectas habere et inter se com parare.-Morgagri. De Sed. et Caus. MTorb., lib. 14. Procemium.

\section{WESTMINSTER HOSPITAL}

\section{TWO CASES OF CYNANCHE TRACHEALIS ; TRACHEOTOMY IN} THE SECOND, FOLLOWED BY DEATH TWENTY-FOUR HOURS AFTER.

\section{(Under the care of Dr. RADCLIFFE.)}

OF the seven cases of croup now recorded, three were submitted to tracheotomy, with the recovery of but one. In the other four no operation was resorted to, and only two recovered. They are not selected to illustrate any special point in the history of croup, but as examples of the disease ordinarily occurring in hospital practice. We may remark that tracheotomy in the young child seems a very uncertain operation, although it cannot be denied that cases here and there do recover in which it has been performed. Many physicians hesitate to recom. mend its adoption until too late. To be o service, it should be had recourse to at an early period, when the vital powers have not become too much depressed by the exhausting effects of the disease.

The notes of the two following cases were taken by $\mathrm{Mr}$. Middleton, house-physician to the hospital :-

CASE 1. - Sarah B-, aged two years and four months, admitted at eleven A.M. on December 3rd, 1860 . Two nights previous to admission she went to bed apparently well ; but on the following morning, after a somewhat restless night, she was observed to breathe with some difficulty, and to have a cough, which gradually became more troublesome during the day, and in the evening was noticed to have a harsh, ringing sound.

At the time of admission to the hospital, the countenance was anxions, flushed, and inclined to be dusky; skin hot and dry; extremities warm; pulse quick; respiration 60 . The cough was frequent, and had a loud brassy tone; the inspiration had the distinctive ringing sound of croup. Bowels open; secretion of urine free; thirst considerable; appetite not entirely lost. Chest well formed; resonant every where in front; posteriorly, marked dulness on percussion over the whole lower third of each lung. Vocal fremitus strongly felt over the whole chest; ordinary sounds of respiration for the most part masked by the tracheal sounds; coarse crepitus occasion. ally distinguishable both in inspiration and in expiration. To have a hot bath containing mustard immediately, and a mixture of two grains of sulphate of copper in two ounces of water: two teaspoonfuls to be taken every ten minutes till vomiting is produced. Hot sponges, changed frequently, to be kept ap. plied to the throat. Vomiting soon occurred, expelling a considerable quantity of flaky matter. - Three P.M.: Pulse 152; respiration 45; skin warm and perspiring freely; countenance improved, and free from duskiness; cough unaltered. To have five minims of dilute nitric acid in three drachms of water every half hour; beef-tea (double strength) and milk to be given every hour, hot.

Dec. 4th. - Ten A.M. : Slept but little, but has not been very restless; takes the medicine and nourishment regularly. Inspiration more prolonged, with much less of the ringing tracheal noise ; pulse 12!; respiration 28 ; skin warm and moist ; countenance calm and of natural colour. In the course of the afternoon the respiratory sounds became more audible throughout 